\title{
Mixed pancreatic apudoma with symptoms of excess vasoactive intestinal polypeptide and insulin: improvement of diarrhoea with metoclopramide
}

\author{
R G LONG, ${ }^{*}$ M G BRYANT, PAMELA M YUILLE, \\ JULIA M POLAK, AND S R BLOOM
}

From the Departments of Medicine and Histochemistry, Hammersmith Hospital, Royal Postgraduate Medical School, London

SUMMARY A female patient is described with a single pancreatic tumour producing vasoactive intestinal polypeptide (VIP), insulin, and pancreatic polypeptide. The initial presentation was with diarrhoea and hypokalaemia and a raised plasma VIP was demonstrated. Her symptoms improved with metoclopramide administration and absolute concentrations of 28 aminoacid (peak IV) VIP were found to have fallen. She then developed hypoglycaemia with hyperinsulinism. All symptoms resolved after surgical excision. This case emphasises the potential of these tumours to contain more than one endocrine cell type synthesising different biologically active peptides.

Pancreatic endocrine tumours are associated with excessive secretion of insulin, gastrin, VIP, ${ }^{1}$ glucagon, ${ }^{2}$ somatostatin, ${ }^{3}$ and pancreatic polypeptide. ${ }^{4}$ In 1965 Law et al. ${ }^{5}$ described a single metastatic islet cell tumour which was demonstrated to be producing gastrin, ACTH, and MSH. ${ }^{2}$ Subsequently a number of case reports of single pancreatic endocrine tumours secreting multiple pancreatic polypeptide hormones have been described; these include combinations of gastrin and glucagon, ${ }^{6}$ insulin and gastrin, ${ }^{7}$ insulin and glucagon, ${ }^{8}$ and gastrin and VIP. ${ }^{9} \mathrm{~A}$ combination of VIP, glucagon, enteroglucagon, secretin, and serotonin is described. ${ }^{10}$ In a series of 35 pancreatic endocrine tumours, Broder and Carter found four tumours secreting two pancreatic hormones (insulin and gastrin in three cases and insulin and glucagon in one case) and one tumour secreting three hormones (insulin, gastrin, and glucagon). ${ }^{11}$ In a series of 24 tumours examined by immunocytochemistry seven stained for more than one of insulin, gastrin, glucagon, and ACTH. ${ }^{12}$ More recently, fasting plasma pancreatic polypeptide concentrations have been

* Present address and address for correspondence: Dr R G Long, St. Thomas' Hospital, London SE1 7EH, England.

Received for publication 30 December 1980 found raised in many patients, including $77 \%$ of VIP-secreting tumours, but this is unassociated with known significant metabolic effects. ${ }^{13}$ Prostaglandin secretion ${ }^{14}{ }^{15}$ and calcitonin ${ }^{15}$ secretion is also recognised.

In the above patients symptoms from one peptide hormone dominated but Hammar and Sale described an adult male with a more than 30 year history of the Zollinger-Ellison syndrome who then developed hypoglycaemia due to excessive insulin secretion by the tumour. ${ }^{16}$ We report a lady with a tumour synthesising three peptides who initially presented with symptoms of VIP excess but who, after resolution of her diarrhoea, hypokalaemia, and plasma peak IV VIP immunoreactivity after metoclopramide administration, developed hypoglycaemia due to hyperinsulinism.

\section{Methods}

Plasma immunoreactive VIP, ${ }^{17} 18$ insulin, ${ }^{19}$ and pancreatic polypeptide ${ }^{20}$ were measured by previously characterised specific radioimmunoassays. Fasting plasma was subjected to gel permeation chromatography. Samples $(1 \mathrm{ml})$ were loaded onto a column of Sephadex G50 superfine $(0.9 \times$ $60 \mathrm{~cm}$ ) and eluted at a flow rate of $3 \mathrm{ml} / \mathrm{h}$, at 
$4^{\circ} \mathrm{C}$, with $0.06 \mathrm{~mol} / 1$ sodium acetate $\mathrm{pH} 5.0$ containing $0.2 \mathrm{~mol} / 1$ sodium chloride. Fractions $(0.5 \mathrm{ml})$ were collected and assayed at two different dilutions to determine immunoreactive VIP content. The column was precalibrated with Dextran Blue, cytochrome C (M wt 12384), pure porcine VIP ( $\mathrm{M}$ wt 3326 ), and $\mathrm{Na}^{125} \mathrm{I}$ ( $\mathrm{M}$ wt 148) as molecular size markers. The coloured markers and $\mathrm{Na}^{125} \mathrm{I}$ were also included with each sample chromatogram as internal markers.

Three portions of the freshly excised tumour were frozen at $-20^{\circ} \mathrm{C}$ for subsequent radioimmunoassay. The portions were weighed, boiled in distilled water, homogenised, and centrifuged. The supernatants were separated and the pellets homogenised again in $0 \cdot 1 \mathrm{M}$ formic acid, centrifuged, and the supernatants separated. All supernatants were then assayed for VIP and pancreatic polypeptide in duplicate in serial dilution. The mean of the peptide concentration of the three portions, which were closely similar, was taken as the concentration of peptide in the tumour. The insulin content could not be accurately measured, as it is unstable in the acid extraction technique used to solubilise the VIP and pancreatic polypeptide.

For immunocytochemistry tissue was frozen in arcton (freon) at $-156^{\circ} \mathrm{C}$ and subsequently freeze-dried and vapour fixed in benzoquinone. ${ }^{21}$ Three $\mu \mathrm{m}$ serial paraffin sections were immunostained by the technique of indirect immunofluorescence using antibodies to insulin, VIP, and pancreatic polypeptide (for dilutions, see Table 1). For the simultaneous demonstration of two peptide hormones in the tissue, the double immunoperoxidase method using two different substrates, 4-Cl-1-napthol (blue product) and diamiobenzidine (brown product) was used. ${ }^{22} 23$ Ultrastructural studies were carried out using tissue fixed in $3 \%$ glutaraldehyde in $0.1 \mathrm{M}$ phosphate buffer $\mathrm{pH} \mathbf{7 \cdot 2}$.

\section{Case report}

A 48 year old white female secretary was admitted to the Hammersmith Hospital, London, in June 1979 with a 12 month history of profuse watery diarrhoea and the loss of $13 \mathrm{~kg}$ in weight to $44 \mathrm{~kg}$. During the previous three months she had had about 20 bowel actions per 24 hours, waking almost hourly at night and with frequent faecal incontinence. For four weeks she had been anorexic and nauseated with intermittent vomiting and had complained of pain and weakness of the hands and calves.

She had a long history of extrinsic asthma and
Table 1 Dilutions and absorption used in two immunocytochemistry techniques

\begin{tabular}{llll}
\hline & Dilutions for immunocytochemistry & $\begin{array}{l}\text { Absorption } \\
\text { (nmol/ml } \\
\text { diluted } \\
\text { antiserum })\end{array}$ \\
\cline { 2 - 3 } & Immunofuorescence & $\begin{array}{c}\text { Peroxidase- } \\
\text { antiperoxidase }\end{array}$ & \\
\hline VIP & $1: 400$ & $1: 2000$ & $0 \cdot 1$ \\
$\begin{array}{l}\text { Pancreatic } \\
\text { polypeptide }\end{array}$ & $1: 3000$ & $1: 12000$ & $0 \cdot 1$ \\
$\begin{array}{l}\text { Insulin } \\
\text { I: }\end{array}$ & $1: 800$ & $1: 800$ & $1 \cdot 0$ \\
\hline
\end{tabular}

on admission was taking beclomethasone, salbutamol, and disodium cromoglycate by inhaler as well as oral codeine phosphate $120 \mathrm{mg}$ and Lomotil 3 tablets daily for her diarrhoea. She had undergone a simple left-sided mastectomy 18 months previously for a small intraduct carcinoma of the breast. There was no family history of endocrine adenomata.

Physical examination confirmed moderately severe asthma, no evidence of recurrence of her breast carcinoma, watery faeces per rectum, and no other abnormal findings. A pancreatic VIPsecreting tumour was diagnosed on the basis of repeatedly raised levels $(n=11)$ of plasma VIP with a mean of $260 \pm 15$ (SEM) pmol/l (normal $<20 \mathrm{pmol} / \mathrm{l}$ ) and an arteriographically and CAT scan proven mass in the tail of the pancreas. Plasma potassium was $2.2 \mathrm{mmol} / 1$, bicarbonate $21 \mathrm{mmol} / 1$, urea $7.0 \mathrm{mmol} / 1$, and fasting blood glucose $3.8 \mathrm{mmol} / 1$. Fasting plasma pancreatic polypeptide was also raised at $240 \mathrm{pmol} / 1$ (normal less than $100 \mathrm{fmol} / \mathrm{l}$ ). Fasting plasma calcium, phosphate, gastrin, glucagon, and somatostatin concentrations were normal.

The stiffness and weakness of her hands and calves resolved on oral potassium replacement and her nausea and vomiting responded to metoclopramide $10 \mathrm{mg}$ three times a day. Unexpectedly this drug also controlled her diarrhoea with reduction of the number of bowel actions to two per 24 hours. Withdrawal of the metoclopramide led to recurrence of severe diarrhoea and reintroduction of the drug again stopped it. This was confirmed on three separate occasions, with a mean daily faecal weight off metoclopramid: of $1100 \mathrm{~g}$ and $260 \mathrm{~g}$ on metoclopramide.

With diarrhoea the concentration of total immunoreactive VIP was $343 \mathrm{pmol} / 1$ and without diarrhoea $230 \mathrm{pmol} / \mathrm{l}$. Gel chromatography of this plasma showed the presence of five peaks (Fig. 1) and the percentage VIP immunoreactivity in each of the peaks is shown in Table 2. The recovery of total VIP-immunoreactivity loaded 


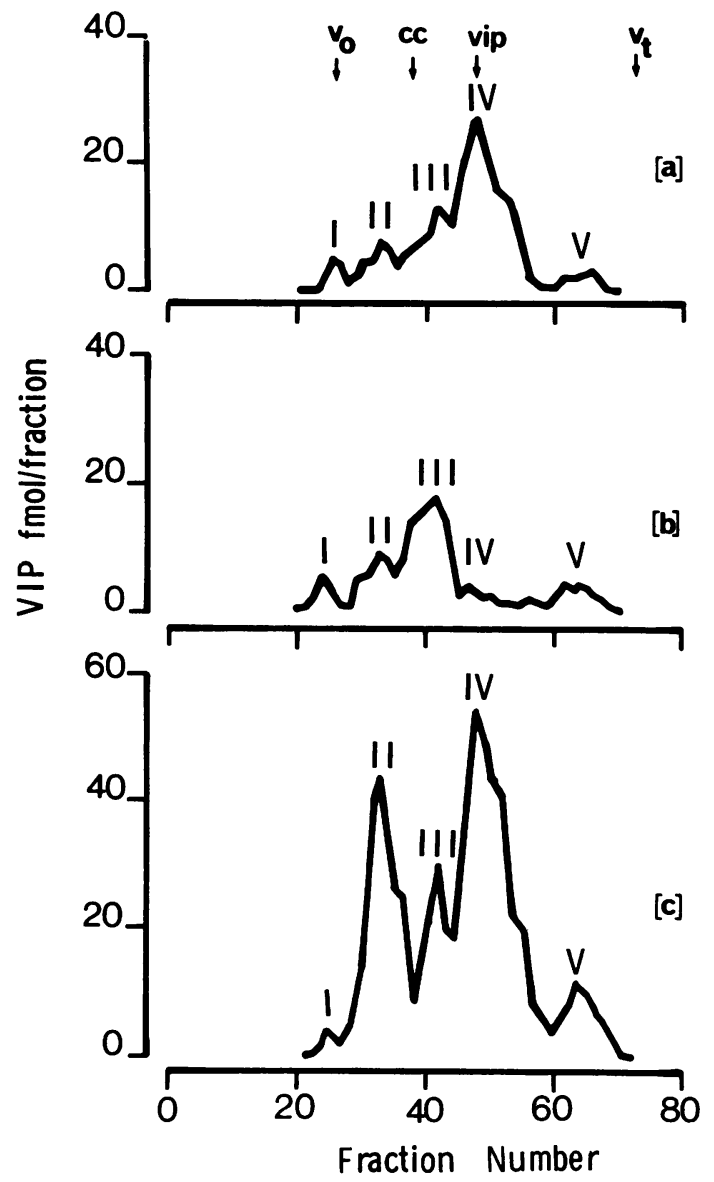

Fig. 1 Immunoreactive VIP gel permeation chromatography profiles of plasma before $(a)$ and after (b) metoclopramide treatment. Panel (c) shows the profile for the tumour extract. Molecular size markers are $v_{o}$ : dextran blue; cc: cytochrome $C$; vip: pure porcine VIP; vt: sodium ${ }^{125}$.

Table 2 Subdivision of VIP gel permeation chromatography profiles into five different immunoreactive peaks*

\begin{tabular}{|c|c|c|c|c|c|}
\hline & \multicolumn{5}{|c|}{ Peaks } \\
\hline & $I$ & II & $I I I$ & $I V$ & $V$ \\
\hline $\mathrm{KaV}$ & & $0 \cdot 15$ & 0.35 & 0.48 & $0 \cdot 80$ \\
\hline $\begin{array}{l}\text { Plasma pre-metoclopramide } \\
\text { treatment }(\%)\end{array}$ & $3 \cdot 5$ & $11 \cdot 7$ & $21 \cdot 4$ & $59 \cdot 8$ & $3 \cdot 5$ \\
\hline $\begin{array}{l}\text { Plasma post-metoclopramide } \\
\text { treatment }(\%)\end{array}$ & $5 \cdot 7$ & $18 \cdot 3$ & $60 \cdot 4$ & $5 \cdot 2$ & $10 \cdot 4$ \\
\hline Tumour extract $(\%)$ & $1 \cdot 0$ & $28 \cdot 4$ & $15 \cdot 6$ & $48 \cdot 8$ & $7 \cdot 2$ \\
\hline
\end{tabular}

on the column was more than $95 \%$. Before metoclopramide treatment the majority of VIPimmunoreactivity corresponded to the elution position of pure 28 aminoacid porcine in peak 4 . After metoclopramide treatment, however, the majority eluted in peak 3 , indicating a VIP-like molecule of greater molecular size. There was therefore an absolute fall in peak 4 immunoreactivity from $205 \mathrm{pmol} / 1$ to $12 \mathrm{pmol} / 1$ and a rise in peak 3 from $73 \mathrm{pmol}$ to $139 \mathrm{pmol} / 1$.

She was discharged home to allow her general condition to improve before elective surgery. Her diarrhoea was still well controlled and she had gained $12 \mathrm{~kg}$ in weight by early August 1979 . However, she then began to complain of faintness and tiredness before meals with rapid improvement after eating. Fasting blood glucose levels were $0.7 \mathrm{mmol} / 1$ and $1.6 \mathrm{mmol} / 1$ with simultaneous insulin levels of 24 and $26 \mu \mathrm{unit} / \mathrm{ml}$ (normal $<5 \mu$ unit/ml with this degree of hypoglycaemia). A diagnosis of inappropriate insulin secretion was made and she was started on diazoxide $100 \mathrm{mg}$ three times a day. She failed to resfond to diazoxide even when the dose was increased to $200 \mathrm{mg}$ four times a day and was admitted to hospital in hypoglycaemic coma (blood glucose $0.7 \mathrm{mmol} / 1$; plasma insulin 32 $\mu \mathrm{unit} / \mathrm{ml}$ ). Subsequently she required four hourly high carbohydrate meals day and night to prevent hypoglycaemia.

At operation on 21 September 1979 (Professor LH Blumgart) a $7.5 \times 6.0 \times 4.0 \mathrm{~cm}$ encapsulated tumour was identified in the tail of the pancreas and a distal pancreatectomy was performed. There was no evidence of any metastases.

She had an uneventful postoperative course, was discharged home on 1 October, and returned to work at the end of the month. At nine month follow-up she had had no untoward symptoms and repeated blood glucose and plasma VIP, pancreatic polypeptide, and insulin estimations have been normal.

\section{TUMOUR STUDIES}

The cut surface of the tumour was firm, slightly lobulated, and greyish-white with areas of degeneration and haemorrhage. Conventional histological stainings (Fig. 2) confirmed the presence of an islet cell tumour composed of several distinct cell types. One group of cells was polygonal in shape and arranged in ribbons separated by amyloid deposits; a second group was composed of more anaplastic cells separated by connective tissue, and the third group was more basophilically stained and had more regular nuclei. The tumour capsule was intact, there was no vascular 


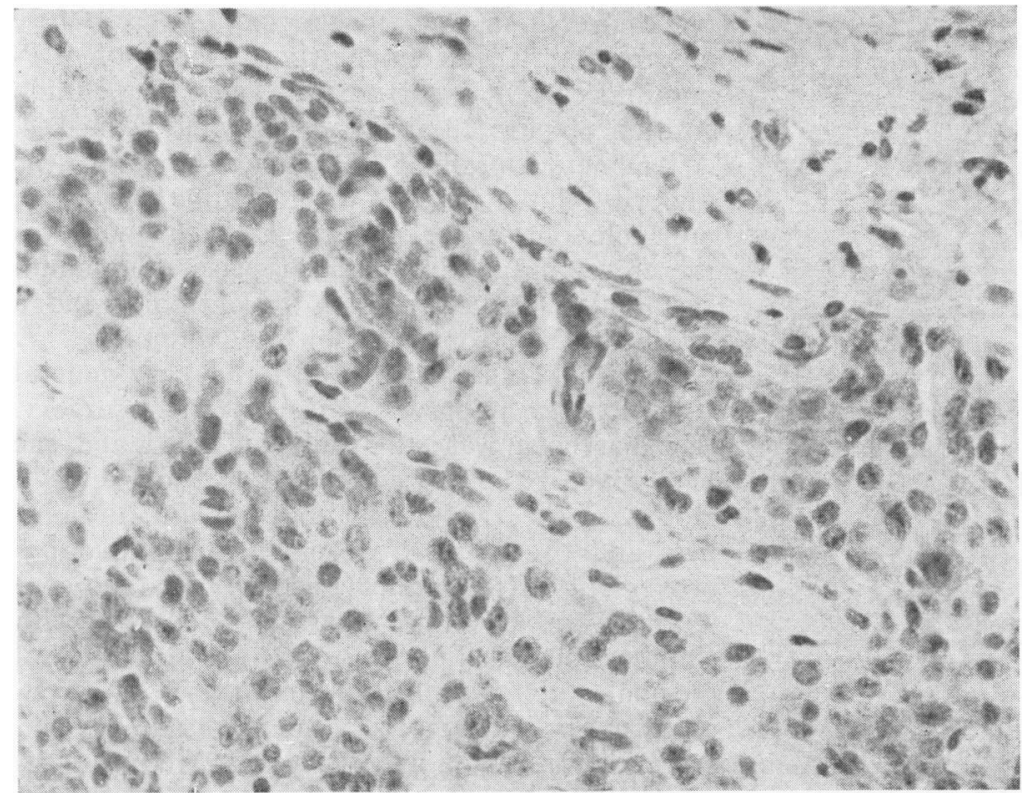

Fig. 2 Conventional histology (haematoxylin and eosin) of the tumour. The clusters of tumour cells are separated by bands of connective tissue and amyloid deposits $(\times 300)$.

invasion in the tumour, and a lymph node and the spleen showed no evidence of tumour cells. The appearances were consistent with a pancreatic endocrine tumour with multiple cell types.

The mean tumour VIP, assessed by radioimmunoassay, was $869 \mathrm{pmol} / \mathrm{g}$ wet tissue. This can be compared with $33 \pm 8$ (SEM) $\mathrm{pmol} / \mathrm{g}$ in histologically normal pancreatic tissue from seven human controls. Chromatographic analysis of VIP-immunoreactivity is shown in Fig. 1 and Table 2. Similar immunoreactive VIP peaks were seen in tumour extract as in plasma and the majority eluted in peaks 2 and 4 . The mean tumour pancreatic polypeptide was $365 \mathrm{pmol} / \mathrm{g}$ wet tissue, which is in the normal range for human pancreas.

Tumour cells reacted with antibodies to VIP, insulin (Fig. 3), and pancreatic polypeptide, but cells staining for VIP and pancreatic polypeptide were relatively sparse. Both immunostaining of the serial sections and the double immunoperoxidase revealed a separate cellular origin for each of the three regulatory peptides. Ultrastructural studies showed the presence of an active and well-granulated tumour containing three types of secretory granules (Fig. 4): one large (200-220 $\mathrm{nm}$ ) with a well-defined wide halo and core resembling insulin granules, ${ }^{24}$ another rather small $(100-130 \mathrm{~nm}$ in diameter) corresponding to VIP secretory granules similar to neurosecretory granules of other vipomas, ${ }^{25} 26$ and a third of medium size with a closely attached membrane resembling PP granules $(120-150 \mathrm{~nm}){ }^{2 i}$

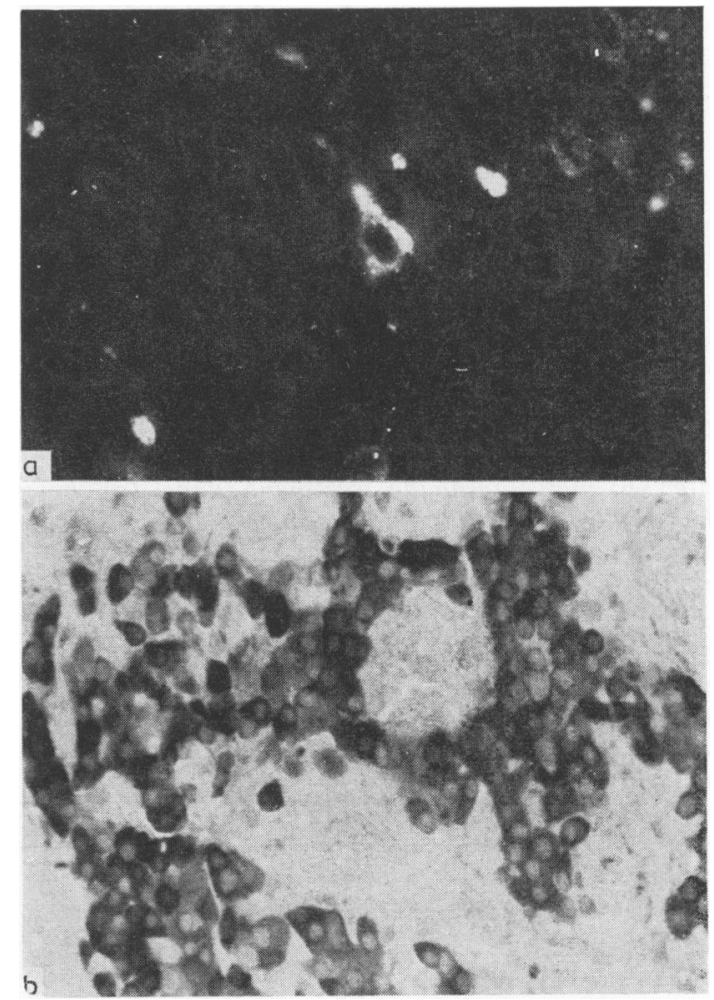

Fig 3 (a) Scattered VIP-immunoreactive cells stained by the indirect immunofluorescent method $(\times 550) .(b)$ Clusters of insulin-containing cells immunostained using the immunoperoxidase method $(\times 550)$. 


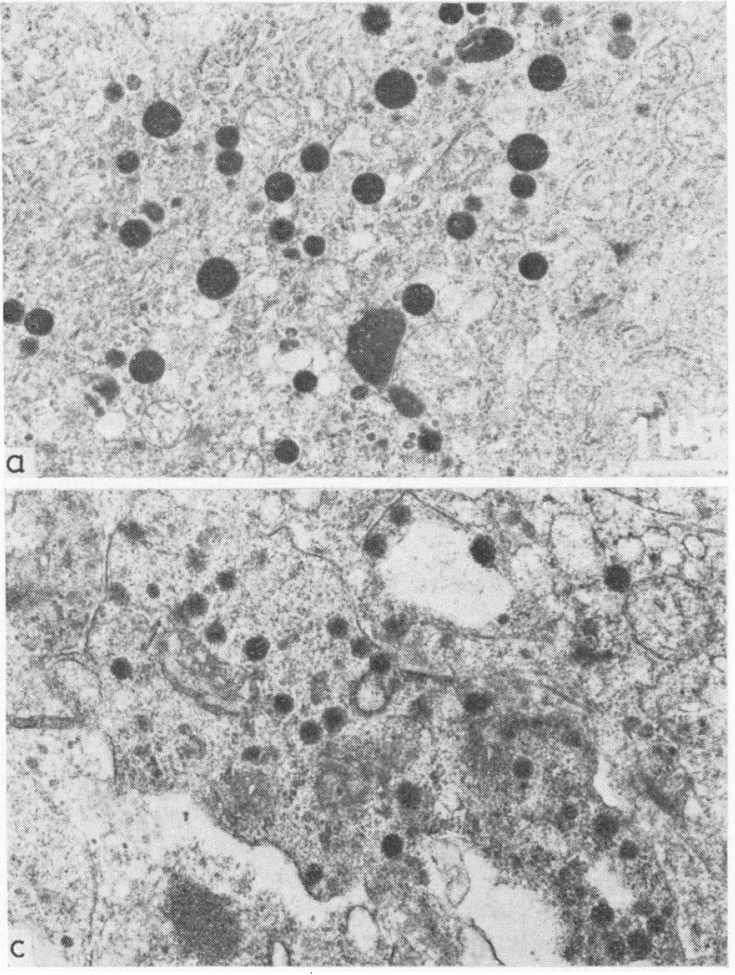

\section{Discussion}

The clinical, biochemical, immunocytochemical, and ultrastructural evidence suggest that this tumour was secreting VIP, insulin, and pancreatic polypeptide. Pancreatic VIP secreting tumours have been previously described which secreted gastrin and pancreatic polypeptide, but these peptides did not cause specific symptoms. It is known that hypokalaemia causes a reduction in insulin secretion ${ }^{28}$ and in this patient it seems possible that hypokalaemia prevented excessive insulin secretion when the diarrhoea was prominent. However, with resolution of the diarrhoea and normokalaemia, excessive insulin secretion with severe hypoglycaemia occurred. VIP is known to increase hepatic glucose mobilisation and the high 28 aminoacid VIP concentrations before metoclopramide treatment may also have played a role in preventing hypoglycaemia.

The list of drugs that may control the diarrhoea of the Verner-Morrison syndrome is growing. Corticosteroids are usually effective in the short-term. Somatostatin reduces intestinal juice secretion and plasma VIP concentrations in the short-term but its more prolonged effects on

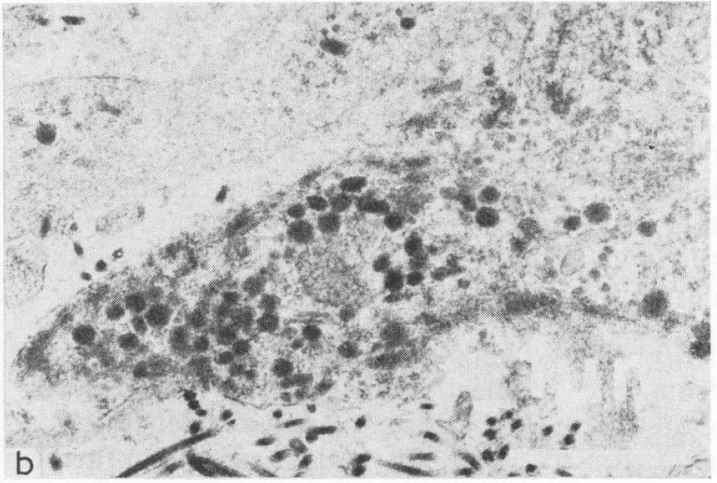

Fig 4 (a) Tumour cell showing large electron dense granules, diameter 200-220 nni (X20000). (b) Tumour cell showing small electron dense granules (100-130 nm) showing a clear halo and a limiting membrane $(\times 30000)$. (c) Tumour cell

showing medium size $(120-150 \mathrm{~nm})$ electron dense secretory granules $(X 30000)$.

diarrhoea have yet to be assessed. ${ }^{29}$ Indomethacin has been reported to reduce diarrhoea and probably acts by suppressing prostaglandin synthesis. ${ }^{30} 31$ Lithium carbonate treatment reduced faecal output in one patient but did not abolish VIP secretion. ${ }^{32}$ The nitrosurea cytotoxic drug streptozotocin can reduce tumour mass and cause long-term remissions. ${ }^{33}$ In this patient metoclopramide stopped the diarrhoea, even though plasma total VIP concentrations were greatly raised. In volunteers intravenous VIP infusion to similar plasma concentrations of plasma VIP seen in this patient result in a failure of absorption in the jejunum of water, sodium, and chloride ${ }^{34}$ and in the colon of water. sodium. chloride, and bicarbonate. ${ }^{35}$ The most marked change in the chromatographic profiles after metoclopramide treatment was the fall in peak 4 immunoreactivity, which corresponds to pure 28 aminoacid porcine VIP, from $205 \mathrm{pmol} / 1$ to 12 $\mathrm{pmol} / 1$. These data show that peak 3 VIP, at least in the concentrations seen in this patient. are not apparently associated with diarrhoea and suggest that peak 2 VIP is also not biologically active. The possibility must exist that peaks 1-3 are biologically inactive precursor molecules. In contrast, peak 4 VIP appears to be most bio- 
logically active and raised plasma concentrations are associated with profuse diarrhoea.

It is becoming increasingly recognised that single pancreatic apudomas frequently secrete more than one of the six tumour secreted peptides. This case demonstrates that if the symptoms due to one regulatory peptide are treated, the symptoms of another peptide may then develop.

Dr Long was supported by a training fellowship from the Medical Research Council. We are grateful to Dr G Bevan, Edgware General Hospital, for referring this patient to us for further management.

\section{References}

${ }^{1}$ Bloom SR, Polak JM, Pearse AGE. Vasoactive intestinal peptide and watery-diarrhoea syndrome. Lancet 1973; 2:14-6.

${ }^{2}$ Mallinson CN, Bloom SR, Warin AP, Salmon PR, Cox B. A glucagonoma syndrome. Lancet 1974; 2:1-5.

${ }^{3}$ Krejs GJ, Orci L, Conlon JM, et al. Somatostatinoma syndrome: biochemical, morphological and clinical features. $N$ Engl J Med 1979; 301:285-92.

${ }^{4}$ Polak JM, Bloom SR, Adrian TE, Heitz P, Bryant MG, Pearse AGE. Pancreatic polypeptide in insulinomas, gastrinomas, VIPomas and glucagonomas. Lancet 1976; 1:328-30.

${ }^{5}$ Law DH, Liddle GW, Scott WH, Tauber SD. Ectopic production of multiple hormones (ACTH, $\mathrm{MSH}$, and gastrin) by a single malignant tumour. $N$ Engl J Med 1965; 273:292-6.

'O'Neal LW, Kipnis DM, Luse SA, Lacy PE, Jarrett L. Secretion of various endocrine substances by ACTH secreting tumours-gastrin, melanotropin, norepinephrine, serotonin, parathormone, vasopressin, glucagon. Cancer 1968; 21:1219-32.

${ }^{7}$ Heitz PH, Steiner H, Halter F, Egli F, Kapp JP. Multihormonal amyloid-producing tumour of the islets of Langerhans in a twelve-year-old boy. Clinical, morphological, and biochemical data and review of the literature. Virchows Arch (Päth Anat) 1971; 353:312-24.

${ }^{8}$ Ohneda A, Otsuki M, Fujiya H, Yaginuma $\mathrm{N}$, Kokubo $\mathrm{T}$, Ohtani $\mathrm{H}$. A malignant insulinoma transformed into a glucagonoma syndrome. Diabetes 1979; 28:962-9.

'Judge DM, Demers LM, Nahrwold DL, Dickman PS, Petrokubi J, Trapudki S. Vasoactive intestinal polypeptide and gastrin-producing islet cell carcinoma. Arch Pathol Lab Med 1977; 101:262-5.

${ }^{10}$ Schmitt MG, Soergel KH, Hensley GT, Chey WT. Watery diarrhoea associated with pancreatic islet cell carcinoma. Gastroenterology 1975; 69:206-16.

${ }^{11}$ Broder LE, Carter SK. Pancreatic islet cell carcinoma. I. Clinical features of 52 patients. II. Results of therapy with streptozotocin in 52 patients. Ann Intern Med 1973; 79:101-18.
${ }^{12}$ Larsson L-I, Grimelius L, Håkanson R, et al. Mixed endocrine pancreatic tumours producing several peptide hormones. Am J Pathol 1975; 79:271-84.

13Bloom SR, Adrian TE, Bryant MG, Polak JM. Pancreatic polypeptide, a marker for ZollingerEllison syndrome? Lancet 1978; 1:1155.

${ }^{14} \mathrm{Jaffe}$ BM, Condon S. Prostaglandins $\mathrm{E}$ and $\mathrm{F}$ in endocrine diarrheagenic syndromes. Ann Surg 1976; 184:516-24.

15Rambaud JC, Nisard A, Modigliani R, et al. Hypercalcitonaemia in vipomas. Lancet 1978; 1:220.

${ }^{16}$ Hammar S, Sale G. Multiple hormone producing islet cell carcinoma of the pancreas, a morphological and biochemical investigation. Hum Pathol 1975; 6:349-62.

${ }^{17}$ Mitchell SJ, Bloom SR. Measurement of fasting and postprandial plasma VIP in man. Gut 1978; 19: 1043-8.

${ }^{18}$ Modlin IM, Bloom SR, Mitchell SJ. Experimental evidence for vasoactive intestinal peptide as the cause of the watery diarrhoea syndrome. Gastroenterology 1978; 75:1051-4.

${ }^{19}$ Albano JD, Ekins RP, Maritz G, Turner RC. A sensitive, precise radioimmunoassay of serum insulin relying on charcoal separation of bound and free hormone moieties. Acta Endocrinol 1972; 70: 487-509.

${ }^{20}$ Björnson OG, Adrian TE, Dawson J, et al. Effects of gastrointestinal hormones on fasting gallbladder storage patterns in man. Eur J Clin Invest 1979; 9:293-300.

${ }^{21}$ Pearse AGE, Polak JM. Bifunctional reagents as vapour and liquid phase fixative for immunocytochemistry. Histochem $J$ 1975; 7:179-86.

${ }^{22}$ Sternberger LA. The unlabelled antibody enzyme method. In: Immunocytochemistry. New Jersey: Prentice-Hall, 1974: 129-71.

${ }^{23}$ Nakane PK. Simultaneous localisation of multiple tissue antigens using the peroxidase-labelled antibody method: a study on pituitary glands of the cat. J Histochem Cytochem 1968; 16:557-60.

${ }^{24}$ Creutzfeldt C, Track NS, Creutzfeldt W. In vitro studies of the rate of pro-insulin and insulin turnover in seven human insulinomas. Eur J Clin Invest $1973 ; 3: 371-84$.

${ }^{25}$ Timson CM, Polak JM, Gavin Chesa $\mathrm{P}$, et al. Retrospective ultrastructural studies of secretory graunles in vipomas. In: Handbook of Pathological Society of Great Britain and Ireland, 3-5 January 1979, 43.

2'Rambaud JC, Galian A, Scotto J, et al. Pancreatic cholera (W.D.H.A. syndrome). Histochemical and ultrastructural studies. Virchows Arch (Pathol Anat) 1975 ; 367:35-45.

${ }^{27}$ Gepts W, Baetens D, de Mey J: The PP cell. In: Bloom SR, ed. Gut hormones. Edinburgh: Churchill Livingstone, 1978: 229-33.

${ }^{28}$ Santeusanio F, Faloona GR, Knochel JP, Unger RH. Evidence for a role of endogenous insulin and glucagon in the regulation of potassium homeostasis. J Lab Clin Med 1973; 81:809-17. 
${ }^{29}$ Lennon J, Bloom SR, Sircus W. Studies on blood levels of vasoactive intestinal polypeptide and pancreatic polypeptide and their relation to clinical behaviour in a case of Verner-Morrison syndrome. Ital J Gastroenterol 1978; 10:104-6.

${ }^{30}$ Mathias JR, Carlson GM. Indomethacin in cholera diarrhoea. Lancet 1976; 2:1024.

31Jaffé BM, Kopen DF, Deschryver-Kecskemeti K, Gingerich RL, Greider M. Indomethacin-responsive pancreatic cholera. $N$ Engl J Med 1977; 297:817-21. ${ }^{32}$ Pandol SJ, Korman LY, McCarthy DM, Gardner JD. Beneficial effects of oral lithium carbonate in the treatment of pancreatic cholera syndrome.
$N$ Engl J Med 1980; 302:1403-4.

3Oberg K, Bostrom H, Fahrenkrug J, Dymling JF, Shaffalitsky de Muckadell OB, Lundqvist G. Streptozotocin treatment of a pancreatic tumour producing VIP and gastrin associated with Verner-Morrison syndrome. Acta Med Scand 1979; 206: 223-7.

${ }^{31}$ Krejs GJ, Fordtran JS, Bloom SR, et al. Effect of VIP infusion on water and ion transport in the human jejunum. Gastroenterology 1980; 78:722-7. ${ }^{35} \mathrm{Krejs}$ GJ. Effect of VIP infusion on water and ion transport in the human large intestine. Gastroenterology 1980; 78:1200. 